\title{
LOSS, GRIEF AND BEREAVEMENT: THE EXPERIENCES OF CHILDREN IN KINSHIP FOSTER CARE
}

\section{Edmarié Pretorius, Eleanor Ross}

\section{INTRODUCTION}

Although there has been a plethora of studies on the impact of HIV and AIDS, there would seem to be a paucity of research on the grief reactions and psychological trauma experienced by children who have been orphaned by the pandemic and have subsequently been placed in foster care families.

Since the beginning of the HIV and AIDS pandemic 25 million people have died of HIVrelated illnesses globally, which represents an incalculable loss of human capital. Each of these deaths is associated with trauma in households and communities. In Sub-Saharan Africa HIV/AIDS has left 12 million children orphaned and made vulnerable by the pandemic (Kidman, Petrow \& Heymann, 2007). In South Africa the number of children orphaned and made vulnerable by HIV and AIDS has reached critical proportions. According to Meintjies and Giese (2004), the model-based calculations of the Actuarial Society of South Africa (ASSA) of the number of orphans in South Africa estimate that 990000 children under 18 had been maternally orphaned and 2.13 million children were paternally orphaned. Of these children, 190000 were double orphans, which resulted in a total estimate of 2.93 million children under 18 who had lost either one or both parents by July 2003. Projections derived from the same model predict that, should no major treatment intervention or behaviour change occur, by 2015 roughly 5.6 million children under 18 will have lost one or both parents.

An analysis of Statistics South Africa's General Household Surveys (GHS) for 2005 and 2007 indicated that in South Africa there were approximately 118564 children living in child-headed households in 2005 and by 2007 the figure had risen to 148000 children. According to the UNICEF Annual Report for South Africa in 2005, an unidentified number of children remained without access to any form of care or support. However, there were an estimated 351735 beneficiaries of foster child grants (FCG) during the 2006/7 financial year (Redpath, 2007). Many orphans are cared for by extended families and the majority of households, in addition to supporting their own families, are struggling to meet the needs of orphans in their care (Deininger, Gracia \& Subbarao, 2003; Mutangadura, 2003). Poverty contributes to the burden of trying to meet the needs of orphans. According to figures from the Presidency, using the All Media Products Survey (AMPS) derived poverty line, in 2007 41\% of South Africa's population was living in poverty, with African households in rural areas being most affected (South African Institute of Race Relations, 2008).

Because of the magnitude of the crisis, the best strategy to address and meet the emotional, physical and social needs of orphans and vulnerable children (OVCs) would seem to be child care programmes within the community. Foster care is one of the most widespread community child care programmes and reflects the belief that the family is the most suitable environment to facilitate healthy growth and the social development of children (Jacobs, Shung-King \& Smith, 2005).

\section{Foster care in the South African context}

Fostering is probably the most widely practised form of substitute care for children worldwide. There is considerable diversity in the way fostering is defined and practised in different 
countries. In some countries it is defined as applying only to children placed through official channels, whilst in others it includes children living in informal arrangements. In some countries foster care is a strictly temporary arrangement, whereas in others the norm is usually a long-term quasi-adoptive arrangement. In South Africa the Children's Act (No. 74 of 1983) does not distinguish between foster care in family foster care settings (kinship foster care) or outside family foster care settings. In South Africa there are four types of foster care placements. These include long-term non-related foster care, kinship or related foster care, intermediary foster care and short-term foster care. A long-term foster care placement is usually with people unrelated to the child and it is designed to provide permanent placement for children as they are unlikely to ever return to their family of origin (Gauteng Task Team on Foster Care Procedures, 2006). Kinship care placement refers to any living arrangement in which children are cared for by a relative or someone with whom they have had a prior relationship. The description includes extended family members such as grandparents, godparents, family friends or any person who has developed a strong emotional bond with the child (Green \& Berrick, 2004).

According to the Discussion Paper of the Children's Act, No. 74 of 1983, which was formulated prior to the adoption of the 2005 Children's Act, family foster care placement (kinship care) is the most general form of foster care in South Africa. Kinship foster care has long been used among African families. It is usually more advantageous than non-related care, because it is easier for a child to adjust to family members whom he or she knows (Messing, 2006). Kinship care helps children ease the pain of losing birth parents and tends to provide familial and cultural continuity (Hegar, 1999; Kang, 2007). A study conducted by Harden, Clyman, Kriebel and Lyons (2004) found that kinship foster parents had fewer social and economic resources than traditional foster parents. This finding is consistent with research carried out by the Child Institute in Cape Town, which revealed that South African kinship foster parents continue to live in poverty despite the provision of foster child grants (Access, 2003). Formal kinship placements are determined by formal legal procedures, whereas in informal kinship arrangements no legal procedures are required. Hence many families apply for formal kinship care because the formal kinship court-ordered care enables the family to apply for a foster child grant, which assists them in alleviating poverty. However, the foster care programme in South Africa, which is predominantly based on kinship foster care, appears to be overburdened with relatives and grandparents being expected to support the increasing numbers of OVCs.

Intermediary foster care placements occur when restoration services are rendered to the biological parent(s) in order to improve their relationship with the child (Gauteng Task Team on Foster Care Procedures, 2006). Short-term foster care placements aim to provide a temporary home for the child, while the parents may be afforded rehabilitation services to improve their situation. Children may be placed in long-term, intermediary or short-term foster care with relatives or non-relatives.

In Section 181 of the Children's Amendment Bill, 2006, the purposes of foster care are summarised as being "to protect and nurture children by providing a safe and healthy environment with positive support and to strengthen and preserve families and family relationships whenever it is in the best interest of the child" (Gerrand \& Ross, 2009:7).

Research studies have revealed that many of the children currently requiring foster care tend to display higher levels of emotional and behavioural disturbances. Therefore they may require more care and nurturing. Given the fact that they come from a recently deprived economic 
background, have experienced trauma and may be HIV positive, their needs may be more complex (Foster, 2002; Gauteng Task Team on Foster Care Procedures, 2006).

\section{The impact of loss on children and adolescents}

The increasing number of children whose parents have died, or are in the process of dying as a result of the AIDS pandemic and other factors, implies that there are a significant number of children who are likely to suffer loss and grief.

Children and adolescents are also likely to experience loss and deterioration in terms of their wellbeing long before the death of their parents. Those in extremely impoverished households may be negatively affected in various ways:

- Their health may be deteriorating as a result of infection;

- They may have inadequate nutrition and insufficient health care;

- Because of parents who are unable to work because of illness or the death of breadwinners, their livelihoods tend to be limited or non-existent;

- They lose their parents to illness and death and also their families, should they be separated from caregivers and siblings and sent to stay with other relatives or carers;

- Their education is often interrupted or discontinued, because they have to take care of sick parents and siblings;

- They tend to miss out on their childhood, because they are compelled to take on the adult roles of supporting the family; and

- Their social networks are likely to be limited because they have to focus on survival.

Children who are adversely affected and orphans are often traumatised and suffer a variety of psychological reactions to parental illness and death. Research studies on children's reactions suggest that they tend to show internalising (depression, rumination, anxiety, social isolation and withdrawal) rather than externalising (aggression and other forms of antisocial behaviour) symptoms in response to trauma (Forehand, Steele, Armistead, Morse, Simon \& Clarke, 1998; Makame, Ari \& Grantham-McGregor, 2002; Sengendo \& Nambi, 1997). In addition, the normal grieving process of a child whose parent has died of AIDS may be complicated by survivor guilt exacerbated by ambivalent feelings towards the sick or dead person. Furthermore, if the parent's illness was not explained to the child or the latter was not afforded the opportunity to share his/her feelings of anger, confusion, sadness and grief, negative reactions may be aggravated (Wild, 2001).

Cognitive, emotional and social development all influence and determine children's and adolescents' understanding of loss and grief. Their interaction with their environment and in particular significant adults in the environment and the events they are experiencing tend to assume critical importance. By the time they are orphaned, the extended family networks that have traditionally been supportive of vulnerable members have been overstretched because family members are often emotionally and physically exhausted.

Howarth and Leaman (2001) describe loss as a state of being deprived of someone or something valuable. However, for young people loss is not only associated with emotional feelings, but also the experience of loss of safety and familiarity (Rowling, 2003).

Although Silverman (2000:45) warns that “...children are not their stages of development", children's reactions and adaptations to loss and death are guided by their developmental stages. When involved in distressful events, children of early primary age can regress to clinging and 
disobedient behaviour. Pre-adolescents usually make an important shift in conceptual development when confronted with death and loss. The experience of trauma in this stage of development can stimulate either mature or regressive behaviour. Social withdrawal is a common sign of fear and worry, and the feelings of helplessness can change to anger, aggression and opposing authority figures, or they might take on the role of the clown. It is also likely that there might be grief without tears (Rowling, 2003).

The development changes during adolescence place young people at particular risk. Because of changing hormonal concentrations their normal emotional reactions are characterised by "ups" and "downs", and experiences of loss might intensify the emotional responses. Louw and Edwards (2004) explain that the development of personal identity is a particularly prominent feature of adolescence. Some adolescents achieve this developmental task with ease and establish their identity; however, many engage in a process of questioning, exploring and experimenting. Sometimes adolescents develop a negative identity, which implies that they have a low self-esteem, are uncertain and confused about their values, and are unsure about what they want out of life. Despite the interest in identity development, little information is available on how the death of a parent influences identity development and the sense of self. Although research findings on how the death of a parent influences the self- concept and self-worth of adolescents vary (Corr \& Balk, 1996; Worden, 1996), the experience of loss may contribute towards the development of a negative identity. According to Worden (1996), the bereaved adolescent is more likely to develop low selfesteem; exhibits more withdrawn and anxious behaviours; and experiences more health problems and greater depression than bereaved pre-adolescents. Experiences of loss affect adolescents' cognitively developed assumptions about the world, its meaningfulness and benevolence, and their own worthiness. It is important to remember, however, that loss experiences challenge personal growth in young people and assist them with their personal development. Older adolescents tend to be more able to contemplate the value of losses experienced and seem to be more focused on creating "meaning" out of their losses. Adolescents might experience a subtle form of anger, which can be manifested in "putting up a wall" or withdrawing from friendships, or trying to cope by diverting emotional pain by using drugs or alcohol, or resorting to promiscuous behaviour (Rowling, 2003).

Showing respect and providing opportunities to increase and maintain personal control are essential support strategies for adolescents and can potentially help them to make sense of their changing worlds and assist them in experiencing personal development and growth. Despite the significant and far-reaching effects of loss and trauma on the emotional wellbeing of children and adolescents orphaned by AIDS, there appears to be a paucity of research focusing on these grief reactions and the support services available to address these needs.

\section{METHODOLOGY}

\section{The aims and objectives of the study}

In order to facilitate evidence-based research the Nelson Mandela Children's Fund (NMCF) undertook collaborative research with the Wits Department of Social Work in 2007/8. The findings from the research were intended to enhance foster care programmes and inform social policy in the area of foster care. The overall purpose of this research was to establish a holistic view of foster care in South Africa by focusing on foster families, foster children and services by $21 \mathrm{NMCF}$ partner organisations located across eight provinces in South Africa. This study viewed children through a human rights lens and formed part of the NMCF's commitment to fostering a rights-based environment for children and youths, and enhancing their lives and 
wellbeing. Among the research questions posed was whether organisations tasked with supporting foster families were helping these children to come to terms with the grief and trauma arising from the loss of their parents.

Some of the objectives relevant to the children involved in the study were:

- To explore the experiences of foster children in South Africa in relation to the social service delivery and support systems;

- To highlight the challenges in foster care identified by foster children in South Africa.

This article addresses only the findings in respect of the emotional and psychological experiences, needs and expectations in terms of service delivery to the foster children in the study.

\section{Research design}

A national cross-sectional survey research design, which incorporated both quantitative and qualitative dimensions, was employed in the study. The research was cross-sectional in nature because data were collected during one week in March 2008 rather than over a longer period.

\section{Sampling}

Purposive sampling, a type of non-probability sampling which depends on the researcher's judgement regarding the characteristics of a representative sample typical of the population, was selected to recruit participants (Bless, Higson-Smith \& Kagee, 2006; Terre Blanche, Durrheim \& Painter, 2006).

A purposive sample of 21 NMCF partner organisations in eight of the nine provinces of South Africa that provide foster care was identified by the NMCF for participation in the study. These organisations were distributed across South Africa as follows: Gauteng 3; Limpopo 2; Mpumalanga 1; North West 1; Free state 2; Eastern Cape 4; Western Cape 2 and KwaZuluNatal 2. Different groups were targeted, i.e. partner organisations, foster parents and foster children (including children with disabilities).

\section{Research instrumentation}

Semi-structured interview schedules comprising closed and open-ended questions were used to collect the required data. According to Bless et al. (2006), a semi- structured interview schedule is very helpful in exploratory research; however, the quality of data gathered depends strongly on the skills of the interviewer. The same interview schedule was used for individual interviews and focus groups. The research instrument was submitted to the NMCF for perusal and it was pre-tested at two organisations within Gauteng. Although the organisations participated in the research process, the staff members, parents and children who participated in the pre-testing were not included in the actual research process. Additional items were incorporated and the research instrument was translated into the eleven official languages of South Africa. Ethical clearance to conduct the study was obtained from the University's NonMedical Ethics Committee.

\section{Data collection}

Research assistants were recruited and 30 were appointed and trained to conduct the research. The research assistants were either students or staff of the University of the Witwatersrand who had a minimum of a three-year degree in the social sciences. During the training of the research assistants, particular attention was paid to preparing them to deal with sensitive issues, providing psychosocial support and responding to the discovery of possible abuse or neglect. The research assistants also transcribed the collected data into English. 
In order to enhance validity and reliability of the study, triangulation was adopted, whereby different data collection methods were used, i.e. interviews and focus groups.

\section{Data analysis}

The demographic information and responses to close-ended questions provided the quantitative data, while the responses yielded by the open-ended questions provided the qualitative data. Close-ended items were analysed using descriptive statistics in the form of frequency counts. Responses to the open-ended items were systematically analysed using thematic content analysis. Emerging themes were identified and analysed and this ultimately resulted in the findings and recommendations.

\section{RESULTS AND DISCUSSION}

The research was conducted with NMCF partner organisations in eight of the nine provinces of South Africa. The data from 237 individual interview schedules and five focus groups with 40 foster children were analysed. Therefore the grand total number of schedules that were analysed was 277 . The 14 spoiled individual interview schedules were either incomplete or the interviews were conducted with children under the age of 12 years, who did not meet the participant selection criteria. The 15 focus group interview schedules that were not analysed were incomplete, involving children under the age of 12 or conducted with children living in an institution who were not necessarily foster children. All the analysed data included both individual and focus group members' responses.

\section{The socio-demographic profile of participants}

The following figures describe the profile of participants in terms of age, gender, educational level, relationship with foster parents and duration of foster care.

Figure 1 depicts the age distribution of foster care children nationally.

\section{FIGURE 1}

AGE DISTRIBUTION OF THE FOSTER CHILDREN (N=277)

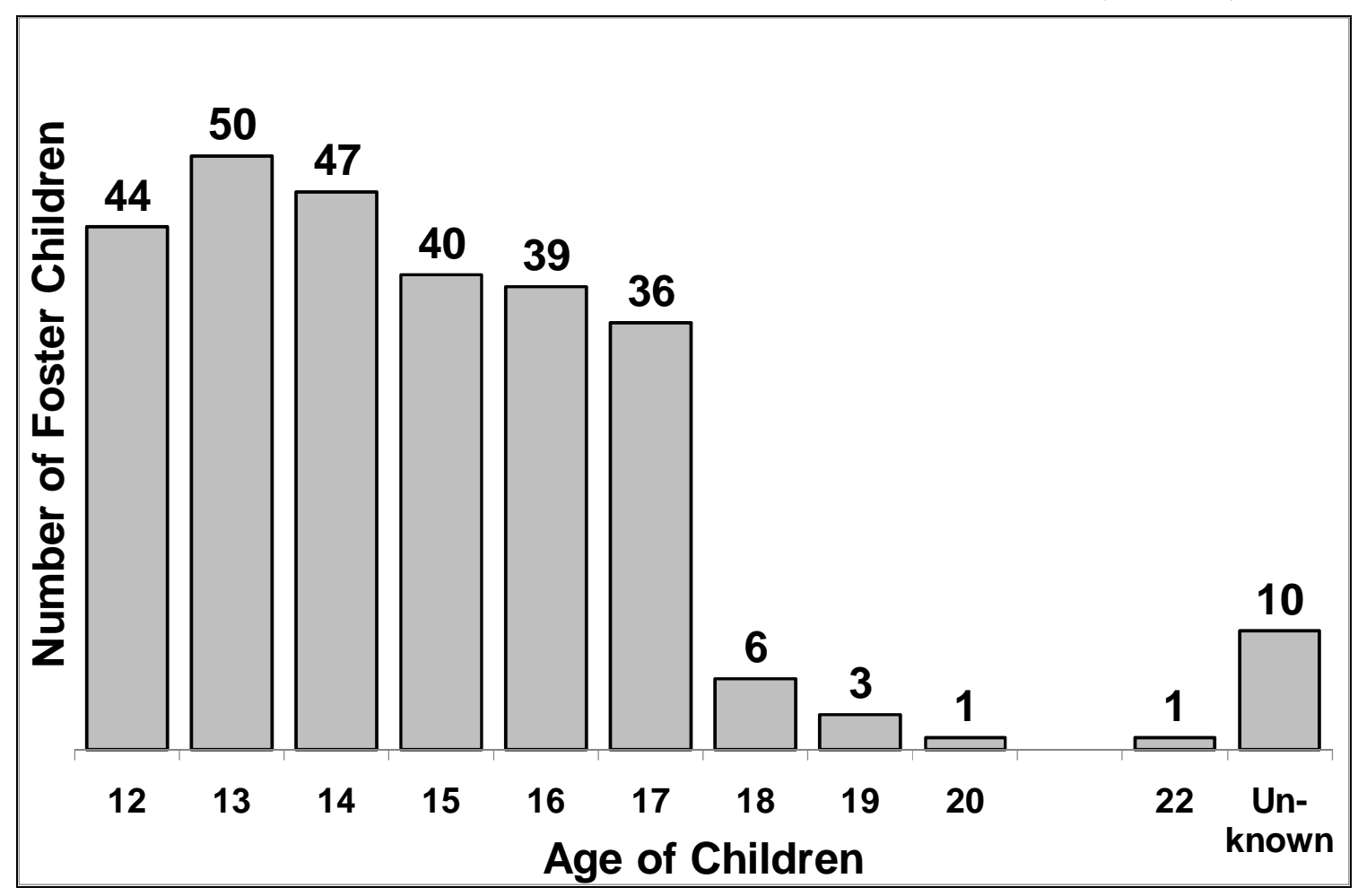


The majority (92\%) of the children were between 12 and 17 years of age, suggesting that most of the children were entering the transition phase of development from being a child to becoming an adolescent. According to Louw and Edwards (2004:516) "...the development of a personal identity seems to be an almost universal requirement of the adolescent stage". Although identity development continues throughout life, adolescents develop a sense of self as they differentiate from parents (Balk, 1995). The formation of identity mainly centres on the establishment of gender roles, relationships, autonomy from parents, a value system, social responsibility and work roles. Cait (2008:323) explains that "...identity and meaning making are bound by helping people understand experiences". Therefore experiences of loss during this developmental stage are likely to affect the healthy development of identity.

Figure 2 shows the gender distribution of foster children nationally.

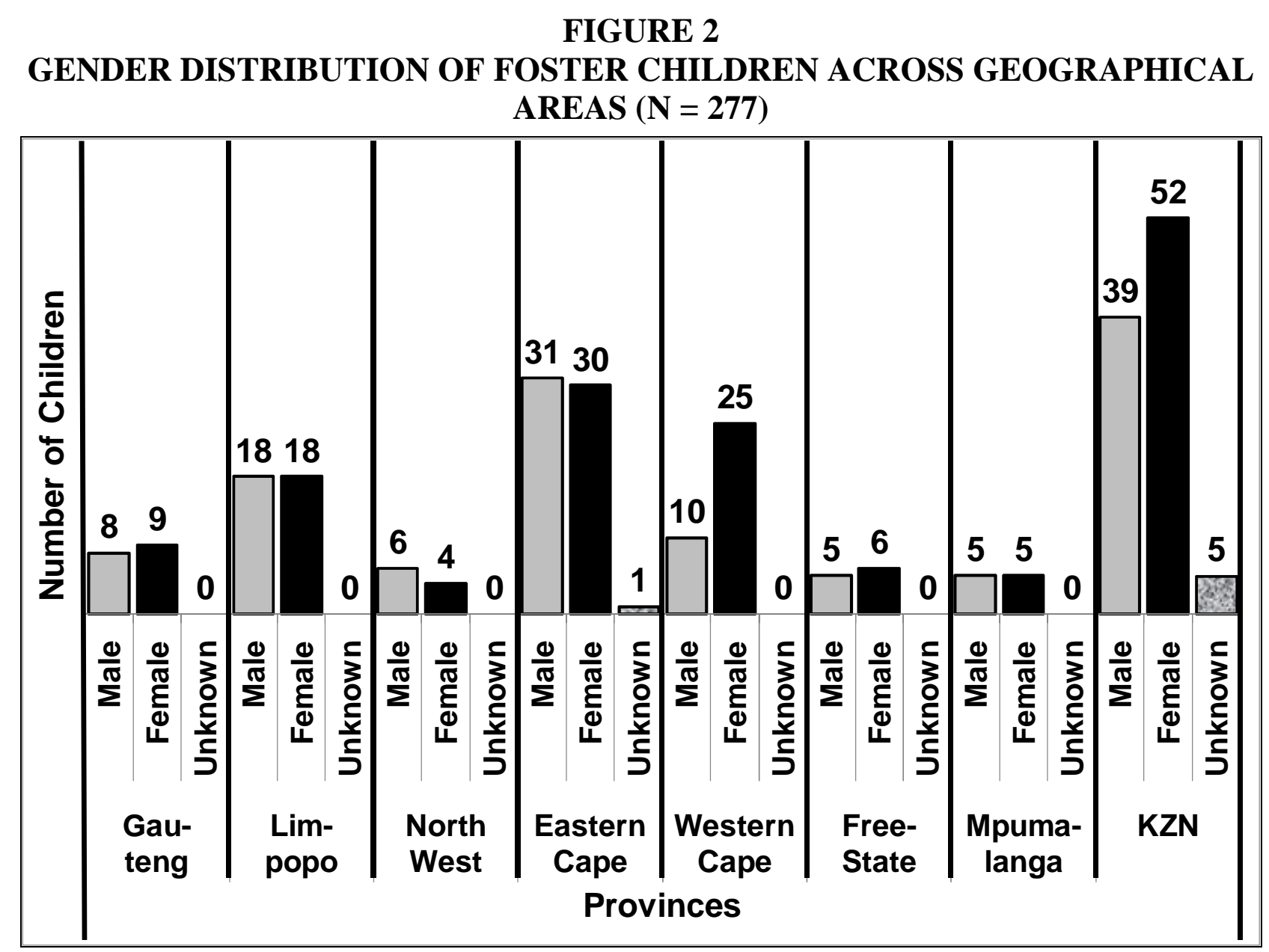

The majority of the foster children (54\%) were female and $44 \%$ were male, with the gender of $2 \%$ being unknown. The two provinces with the highest number of foster children are KZN with 35\% and Eastern Cape with 22\%. Consistent with the findings, the UNAIDS 2008 Report on Sub-Saharan Africa AIDS epidemic update Regional Summary reflects that in 2007 approximately $55 \%$ of all South Africans infected with HIV lived in KwaZulu-Natal and Gauteng.

HIV prevalence amongst pregnant women was reported to be the highest in KwaZulu-Natal $(39 \%)$ and the lowest in the Northern Cape (15\%), Western Cape (16\%) and Limpopo (19\%). In the other five provinces, at least $25 \%$ of pregnant women tested HIV positive.

Figure 3 indicates the educational level of foster care children nationally. 


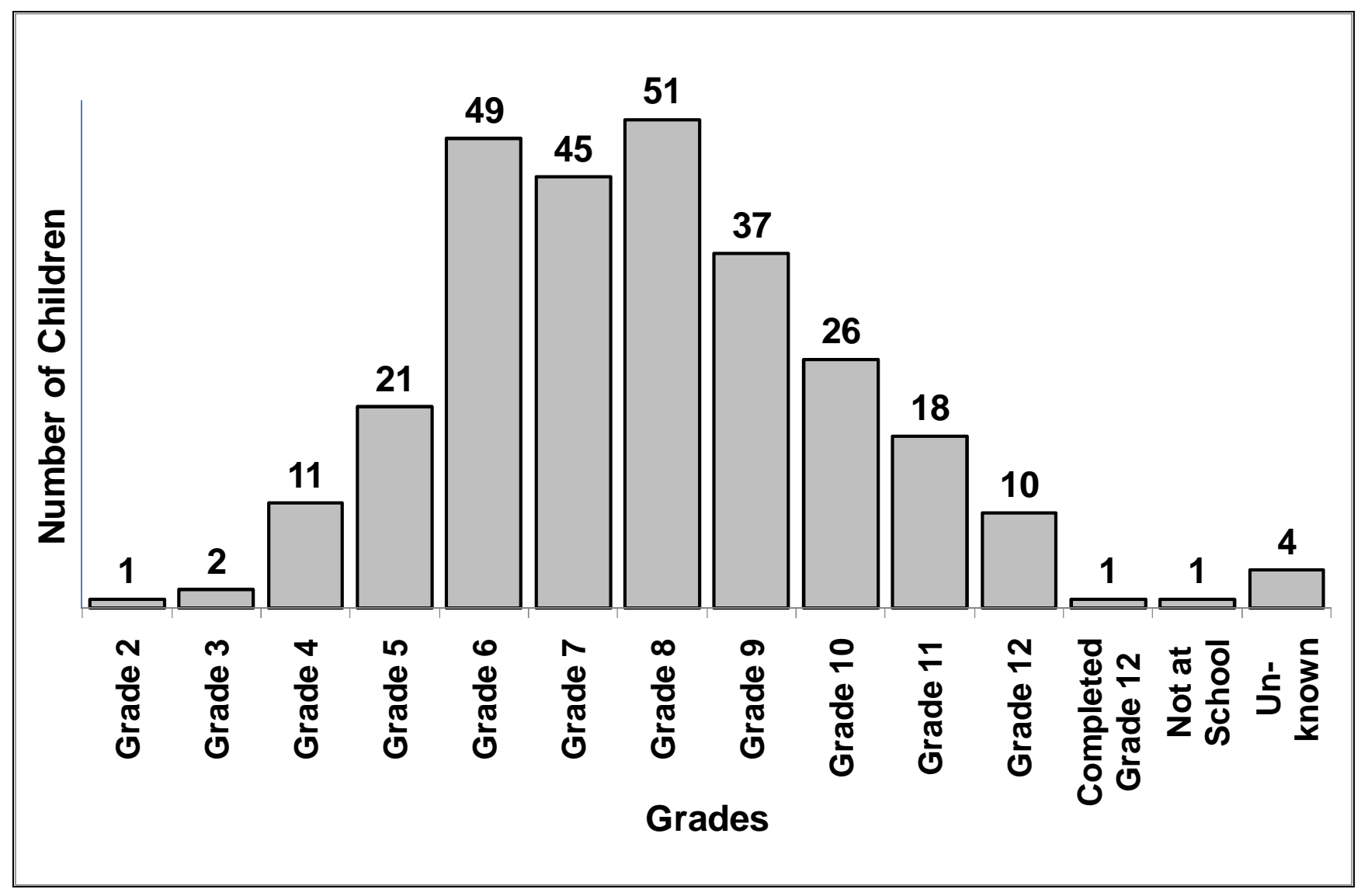

Almost all $(97.8 \%)$ of the foster children were in Grades 2-12. Of the $97.8 \%$ of school-going children, $46.6 \%$ were in Grades $2-7$ and 51,3\% were in Grades 8-12. Only $0.4 \%$ had completed Grade 12 and $0.4 \%$ did not attend school. The educational level of $1.4 \%$ of children was unknown. Acquiring an education, having school uniforms and being able to pay school fees were very important to the participants and almost all of them $(97 \%)$ indicated that they wanted to study at tertiary level and qualify in one or other direction. With reference to the hierarchy of needs proposed by Maslow, it is clear that when a pressing need becomes satisfied, e.g. having a school uniform and being able to pay school fees, other needs may become the focus, e.g. tertiary education and higher education (Louw \& Edwards, 2004).

Figure 4 highlights the relationship between foster parents and foster children in eight provinces. 
FIGURE 4

RELATIONSHIP OF THE FOSTER PARENT WITH THE FOSTER CHILD (N = 277)

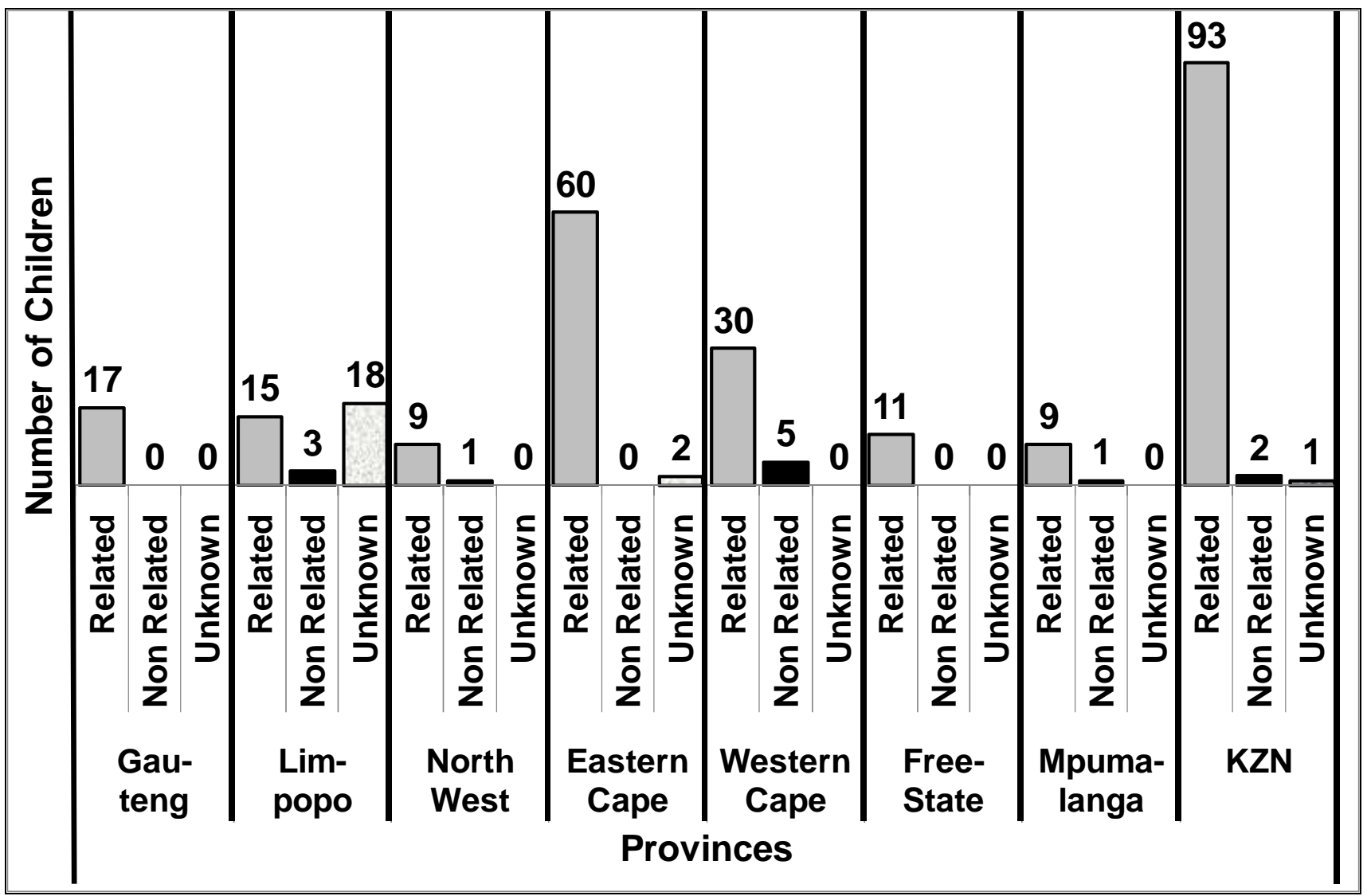

The majority $(88 \%)$ of the foster children were placed in the care of relatives. According to Wilson and Chipunga (1996), the foster care model where children are placed within the family is one of the fastest-growing types of foster care in the United States of America. Kinship care as a foster care model was particularly evident in this study and would also seem to be the preferred model of foster care within the broader South African context. A study conducted by the National Welfare, Social Service and Development Forum (NWSSDF), commissioned by the Department of Social Development in 2007, confirmed that the majority of South African children in foster care are in the care of extended family members, specifically grandmothers or aunts. According to Figure 4, most of the foster parents were related to the children, i.e. grandmothers $(34.8 \%)$, grandfathers $(0.8 \%)$, grandparents $(8.2 \%)$ or a combination of an aunt or uncle with a grandparent $(5.7 \%)$. Hence in $49.5 \%$ of the foster care placements the grandparents were involved in taking responsibility for the children. The implication is that the burden of providing for the physical, emotional and financial needs of the foster children was being shouldered by individuals in the old-age phase of the life cycle.

Research studies by Alpaslan and Mabutho (2005), Mokone (2006) and Van Rensburg and Green (2006) showed that, although elderly grandmothers do have positive experiences when taking care of their grandchildren, they have to face many challenges like poor health, financial strain, isolation in the community because of stigmatisation, and adolescent grandchildren who do not necessarily accept their authority. According to Wallace (2001:128) “...grandparents raising grandchildren are stressed because of feelings of grief, guilt or anger towards their sons and daughters who are not parenting their own children".

Figure 5 depicts the number of years the foster care child was in the particular foster home. 


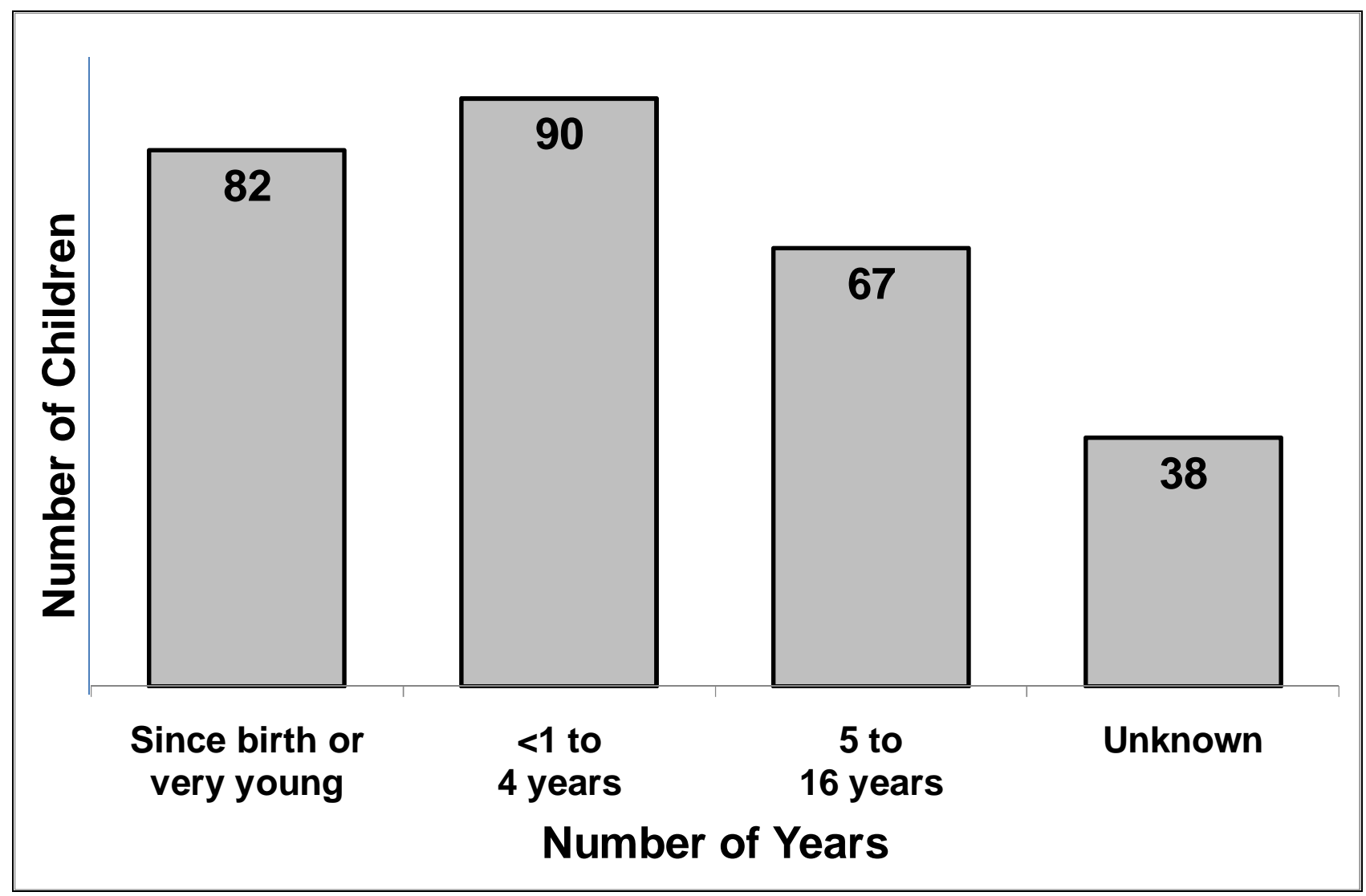

Of the foster children in the study, $32.5 \%$ had been in the particular foster care home less than one to four years and $13.7 \%$ of the children did not know how long they had been part of the household. However, $29.6 \%$ of the children had been in the particular foster home from birth or from a very young age and $24.2 \%$ of the children had been in the particular foster home between five and 16 years. Therefore the highest number of children $(53.8 \%)$ had been part of the same foster household for their entire lives. This finding confirms the kinship model of foster care, where children are cared for by their relatives within their own ethnic group and culture.

It was clear from the analysed data that the majority of children $(72.2 \%)$ were in foster care because their parents were deceased. The reasons for being in foster care were reflected in the following responses:

A girl aged 14 years stated: "My parents died - I have been living with my uncle...".

"My parents passed away when I was very young", a 13 year-old female recalled.

A girl aged 12 and a boy aged 13 stated: "My parents passed away".

Just over one quarter (27.8\%) were born and grew up in the home of a relative, e.g. aunt, brother or sister, but mostly grandmothers.

A boy aged 12 explained: "I do not know. We lived here since I was very young, I don't know both my parents".

A 14 year-old boy stated: "I have always lived with my grandparent". 


\section{The emotional and psychological experiences of children in foster care}

When asked about their feelings before and during the initial stage of the foster care, the children expressed emotions that ranged from sad and unhappy, ambivalent and neutral, to happy and thankful. However, most of the children experienced profound sadness when their parent/s passed away and mentioned that it was a very painful experience. The responses of the foster children reflected a degree of ambivalence and a degree of confusion.

\section{Sub-theme 1: Sad and unhappy}

A young male of 19 years explained: "I was sad and I was unhappy when mommy died..."

"I was not very happy because I missed my mother", said a 13-year-old girl living with her grandmother.

“I felt sad and heartbroken”, stated a 15-year-old female living with her grandparent.

"At first I was very unhappy, because other children use to tease me that I have no parents, I belong to the social services", was the recollection of a boy of 14 years.

"I am unhappy because my basic needs such as school fees, food and clothes are not met", explained a 17-year-old young man living with his older brother.

"It is difficult without my biological mother, people treat you differently from their own children” stated a 12-year-old male.

A 14 year-old boy commented: "It's not easy because people tease us because we depend on social services for survival”.

\section{Sub-theme 2: Worry and fear}

"We were worried that they will not treat us well", stated a 15-year-old male and 17-year-old female living with their aunt.

"When I started living with my grandmother I was scared of her, but right now I am used to her”, said a 12-year-old boy.

"I am unhappy because when my aunt comes back from the bar with her boyfriend, she wakes us up and insults us and wants to kick us out of the house”, explained female siblings of 12 and 13 years of age respectively.

\section{Sub-theme 3: Ambivalent and neutral}

A 12-year-old boy living with his grandmother stated: "I was young so I am not sure exactly how I felt but I guess I was happy”.

“When my parents passed away I was already staying with my grandmother", explained a 12year-old boy.

\section{Sub-theme 4: Happy and thankful}

A young female of 17 years explained: "I felt grateful; at least there was someone to take care of $m e$ ".

"I was glad to live with my grandmother because she takes good care of us", stated a 13-yearold boy.

A 15-year-old girl living with her grandmother explained: "I was glad that I did not have to live with people that I was not related to".

"I am very happy and connected to my foster family now”, said a 15-year-old girl. 
480

A 17-year-old young man explained: "I am so happy with my foster family; we get along very well together".

"I am very happy, I feel at home and I do not feel like an orphan", explained a 12-year-old girl living with her grandmother.

"I am fine because my aunt treats me like her own daughter", said an 18-year-old young female.

\section{Sub-theme 5: Loss, grief and bereavement}

The vast majority of the participants $(85 \%)$ emphasised that, despite the fact that their basic needs in terms of food, clothes and shelter were met, they nevertheless found it difficult to deal with the losses, which affected their adjustment. They shared feelings of sadness, exclusion, unfairness, loneliness and sometimes anger. It seemed that their psychological needs of love, acknowledgment, belonging, nurturing and caring were not necessarily addressed sufficiently, as reflected in the following responses:

"I miss my mother and think about her all the time", stated a 12-year-old girl.

A 14-year-old boy explained: "It is not nice being an orphan, I think about my mother and feels angry because she died when I was a baby and I never got to meet her".

"I miss my mother and when I think about her I feel like crying because I remember how she used to support us emotionally and financially”, stated a 17-year-old young man.

"I have no one to talk to about secret matters. If my mom was here, I'll be able to tell her how I feel, she understood better than anyone”, said a 16-year-old young female living with her grandmother.

A 15-year-old girl commented: “When school friends talk about mothers and you....can't, it's like you do not have a complete life in a way. At the same time it's like I don't have parents. When everybody else is talking about their mothers it makes you feel empty and alone".

“We don't belong anywhere and miss our mother”, said two female siblings aged 12 and 13.

For adolescents it may feel as if their world has been shattered when a parent dies and their sense of self may become confused. How they make meaning of the world is seriously challenged. During the process of development and maturity they find ways to integrate the death into their lives and put the different pieces together. However, to achieve this resolution involves self-awareness, introspection and self-evaluation. The reconstruction that they have to endure can influence their sense of identity. Without understanding how adolescents' identity and sense of self are influenced by loss and death, social workers are likely to grapple with the nature of adolescent bereavement (Cait, 2008).

Most of the foster children who participated in this study seemed to have adjusted well within their foster homes, despite the pain and sadness they had experienced in terms of the death of one or both parents. "It is much better as one has now settled down and memories are beginning to sink", stated a 17-year-old young man living with a grandparent. A young female of 15 years stated: "I was sad about mom's death, but living with grandmother is very nice. She is the only person who has been around for ever".

It was also clear that most of them were treated with respect, love and dignity. For example, a young man of 17 years of age commented: "Although I was sad, my aunt treated us very well. She is very loving”. 
A small minority (5\%) complained that their basic needs were not always met, which related to the long process of application for foster grants. "I am not happy, because sometimes we go to sleep without food because the foster grant has been blocked", stated a 15-year-old girl living with her aunt.

In terms of Maslow's hierarchy of needs theory (Louw \& Edwards, 2004), food is one of the physiological needs which is the most basic need to be met. Should this need not be substantially satisfied, the next need cannot be actualised and the motivation and development of individuals are affected. This may cause the children to become despondent and angry. In turn these reactions may hinder the achievement of a positive identity on the part of the adolescent and may contribute to the development of low self-esteem.

Hardly any malpractices were reported in terms of the grant money, except for one participant $(0.4 \%)$ who commented that she was moved from the foster placement with her grandmother to another foster placement because the money was not used appropriately.

\section{Foster children's contact with siblings and their extended families}

The majority of foster children $(85 \%)$ were placed in foster care with their siblings. A few of the children $(1.8 \%)$ were the only children of their parents. All the comments related to being placed together reflected the feeling that they enjoyed being together as it gave them a sense of family, unity and togetherness.

“Yes I am happy about it because we are family", said a 17-year-old young man living with his uncle and grandmother.

A 16-year-old female commented: "I live with my brother and sisters. We are not separated and it feels very good to have my family under one roof".

A 15-year-old girl living with her older sister explained: "I stay with all my siblings and I appreciate it as we are a family".

The fact that most of the foster care placements were with relatives suggested that the children were in regular contact with their immediate extended families and the majority of them (86\%) had contact with the rest of their extended families, who lived in other towns, cities or provinces. A small group of the participants (8\%) mentioned that, although they had contact with the extended family, it was not on a regular basis because they lived in different provinces. Only $14 \%$ had no contact with their extended families. It seemed that, although children were placed in the care of one particular family member, all relatives that could afford to do so contributed to meeting the basic needs of the children.

\section{Foster children's experiences of social workers rendering foster care services}

More than $60 \%$ of the foster children indicated that no social worker engaged with them prior to the foster care placement. Most of the foster care placements were with relatives and it was clear that it was often a family decision that the child would live with one of the family members, which would appear to be a common cultural practice in many African families.

"After my mother's funeral there was a family meeting and it was decided that I should move here”, stated a female whose age was unknown.

A young boy of 14 recalled: "When my parents passed away the elders reached a decision that I should stay with my grandparents”. 
Where there was an intervention from the social worker, the feedback showed that it was focused predominantly on the physical needs and practical issues around foster care, and the emotional and psychological needs of the children were either attended to in a rather superficial way or not addressed at all. According to Gleeson, O’Donnell and Bonecutter (1997:803), "service needs may be even greater for children in kinship care than for those in the care of nonrelatives, since kinship caregivers tend to be older, have fewer financial resources and have more health problems than nonrelative foster parents".

A 15-year-old boy living with his grandmother stated: "I have never met a social worker in my life; this is despite the fact that my foster care application was approved".

“The social worker helped me to receive a child support grant”, explained a 14-year-old boy.

A 17-year-old female commented: "The social worker counselled me several times and visited me regularly at home”.

"Yes, she visits regularly, arranges for us to get clothes, meet other children and go on the trips organised for the OVC”, stated a 13-year-old girl.

In the majority of cases it seemed that the social worker visited the foster parents and mainly engaged with them. Sometimes they would also visit the children at school. "No, not actually they come to check on me”, said a 13-year-old girl.

A 14-year-old boy stated: “...but we need a social worker to visit and check out the home situation and help in cases where there is a problem".

It seemed that the preparation processes with the child as well as with the potential foster parents were not implemented adequately. The social worker also focused on and engaged very much on the level of ensuring that the physical needs of children were met. The research results, however, showed that there was a great need for emotional and psychological support and assisting the children to deal with all the losses they were experiencing at a young age. These findings could be partly explained in terms of the current shortage of South African social workers and the skills crisis confronting the profession. Consequently, there is a paucity of social workers needed to implement the necessary screening of potential foster parents, render appropriate services and to provide sufficient psychosocial support for foster parents and children. There is also a concern about the quality of services offered by inexperienced social workers and social auxiliary workers, which affects the overall service delivery of foster care programmes in South Africa (Recruitment and Retention Strategy of the Department of Social Development, 2006). This finding is consistent with a research study conducted by Maphanga (2007) in which foster parents who were interviewed clearly stated that social workers did not provide emotional support or guidance in dealing with the challenges of foster parenthood, especially in relation to teenage foster children.

\section{CONCLUSIONS AND RECOMMENDATIONS}

The implementation of the kinship model of foster care would seem to be an appropriate model to address the rapidly expanding need for foster parents in South Africa. However, kinship foster care would appear to be overburdened - particularly where relatives and grandparents are expected to support increasing numbers of orphaned and vulnerable children. Most of the children in this study were entering the transition phase from being a child to becoming an adolescent, which is one of the most challenging stages in human development. It was evident from the data that, although the children might have been part of the household since birth, the losses they experienced affected them emotionally in so many different ways. If they are not 
afforded opportunities to deal with these losses, it is likely to have consequences for their development but more specifically on their development of an identity.

Although social workers assisted the foster families with the grant applications and food parcels, it was clear that there were also needs and expectations in terms of emotional support and guidance as to how to manage the new situation that were not adequately addressed.

The non-probability, purposive nature of the sample precludes generalisation of findings to the broader population of children in foster care. Nevertheless, the findings suggest the following recommendations for service delivery:

- Social workers rendering social services need to improve their effectiveness and streamline the grant application processes so that more time is available for psychosocial support. In this respect greater use needs to be made of social auxiliary workers, who could potentially relieve social workers of some of their administrative tasks;

- Social workers should not only focus on the administrative and concrete needs of the foster family and child, but should assess the emotional and psychological needs, and render psychosocial services to both the foster family and the foster child.

\section{REFERENCES}

ACCESS. 2003. Children speak out on poverty: report on the access child participation process. Cape Town: University of Cape Town Press.

ALPASLAN, A.H. \& MABUTHO, S.L. 2005. Caring for AIDS orphans: the experiences of elderly grandmother caregivers and AIDS orphans. Social Work/Maatskaplike Werk, 41(3):276-295.

BALK, D.E. 1995. Adolescent development: early through late adolescence. Pacific Grove: Brooks/Cole Publishing Co.

BLESS, C., HIGSON-SMITH, C. \& KAGEE, A. 2006. Fundamental social research methods: an African perspective ( $4^{\text {th }}$ ed). Zambia: Juta and Company Ltd.

CAIT, C. 2008. Identity development and grieving: the evolving process of parentally bereaved women. British Journal of Social Work, 38(2):322-339.

CHILD CARE ACT 74/1983. [Online] Available: http://www.info.gov.za/gazette/acts. [Accessed: 08/06/2009].

CORR, C.A. \& BALK, D.E. 1996. Handbook of adolescent death and bereavement. New York: Springer Publishing Company.

DEININGER, K., GARCIA, M. \& SUBBARAO, K. 2003. AIDS-induced orphanhood as a systemic shock: magnitude, impact and program interventions in Africa. World Development, 31(7):1201-1220.

FOREHAND, S.R., STEELE, R., ARMISTEAD, L., MORSE, E., SIMON, P. \& CLARKE, E. 1998. The family health project: psychosocial adjustment of children whose mothers are HIVinfected. Journal of Consulting and Clinical Psychology, 66:513-520.

FOSTER, G. 2002. Supporting community efforts to assist orphans in Africa. New England Journal of Medicine, 346:1907-1910.

GAUTENG TASK TEAM ON FOSTER CARE PROCEDURES. 2006. Foster care procedures guidelines. Department of Social Development: Unpublished manuscript. 
GERRAND, P. \& ROSS, E. 2009. Permanent kinship care via court-ordered foster care: is the system justified? The Social Work Practitioner-Researcher/Die Maatskaplikewerk Navorser-Praktisyn, 21(1):4-22.

GLEESON, J.P., O’DONNELL, J. \& BONECUTTER, F.J. 1997. Understanding the complexity of practice in kinship foster care. Child Welfare, 76(6):801-826.

GREEN, R. \& BERRICK, J.D. 2004. Kinship care: an evolving service delivery option. Children and Youth Services Review, 26(7):657-671.

HARDEN, B.J., CLYMAN, R.B., KRIEBEL, D.K. \& LYONS, M.E. 2004. Kith and kin care: parental attitudes and resources of foster and relative caregivers. Children and Youth Services Review, 26(7):1000-1016.

HEGAR, R.M. 1999. The cultural roots of kinship care. In: HEGAR, R.L. \& SCANNAPIECO, M. (eds) Kinship foster care: policy, practice and research. New York: Oxford University Press.

HOWARTH, G. \& LEAMAN, O. (eds) 2001. Encyclopedia of death and dying. London: Routledge.

JACOBS, M., SHUNG-KING, M. \& SMITH, C. 2005. South African child gauge. Cape Town: Children's Institute.

KANG, H. 2007. Theoretical perspectives for child welfare practice on kinship foster care families. Families in Society, 88(4):575-582.

KIDMAN, R., PETROW, S.E. \& HEYMANN, S.J. 2007. Africa's orphan crisis: two community-based models of care. AIDS Care, 19(3):326-329.

LOUW, D.A. \& EDWARDS, D.J.A. (eds) 2004. Psychology an introduction for students in Southern Africa ( $2^{\text {nd }}$ ed). Sandton: Heinemann.

MAKAME, V., ARI, C. \& GRANTHAM-McGREGOR, S. 2002. Psychological well-being of orphaned children in Dar El Salaam, Tanzania. Acta Peadiatrica, 91:459-465.

MAPHANGA, M.W. 2007. The perceptions of foster parents on how their emotional needs are addressed by social workers at the Johannesburg Department of Social Development following placement of foster children in their care. Johannesburg: University of the Witwatersrand. (Unpublished B.A. Social Work honours research report)

MEINTJIES, H. \& GIESE, S. 2004. Addressing the impact of HIV/AIDS on children in South Africa - priorities for funders and development agencies. A joint working paper of the Children's Institute and the Centre for Actuarial Research. Cape Town, South Africa: University of Cape Town.

MESSING, J.T. 2006. From the child's perspective: a qualitative analysis of kinship care placements. Children and Youth Services Review, 28(12):1415-1434.

MOKONE, J.M. 2006. Challenges experienced by grandparents raising grandchildren: an exploratory study. Social Work/Maatskaplike Werk, 42(2):187-200.

MUTANGADURA, G. 2003. How communities help families cope with HIV/AIDS in Zimbabwe. In: SINGHAI, A. \& HOWARD, W.S. (eds) The children of Africa confront AIDS. Athens: Ohio University Press.

NATIONAL WELFARE, SOCIAL SERVICE AND DEVELOPMENT FORUM 2007. Children's Amendment Bill: proposed alternative approach to the care of orphans and 
vulnerable children in long-term kinship care in response to the crisis which has arisen in foster care provision. [Online] Available: http://www.ci.org.za/depts/ci/pir/pdf/pubichearings/ gauteng/Submissions/Posthearing/nwssdfcbillsubmission [Accessed: 08/06/2009].

REDPATH, J. 2007. Parallel lines: policies relevant to child safety in South Africa. Centre for Justice and Crime Prevention, Monograph Series, No 2, Cape Town.

RECRUITMENT AND RETENTION STRATEGY OF THE DEPARTMENT OF SOCIAL DEVELOPMENT 2006. Pretoria: Government Printers.

ROWLING, L. 2003. Grief in school communities. Effective support strategies. Buckingham: Open University Press.

SOUTH AFRICAN INSTITUTE OF RACE RELATIONS (SAIRR). 2008. Today: unemployment and poverty - an overview. [Online] Available: http://www.sairr.org.za/sairrtoday/news_item.2008-11-28.9488661622. [Accessed: 18/06/2009].

SENGENDO, J. \& NAMBI, J. 1997. The psychological effect of orphanhood: a study of orphans in Rakia District. Health Transition Review, 7:105-124.

SILVERMAN, P.R. 2000. Never too young to know: death in children's lives. New York: Oxford University Press.

STATISTICS SOUTH AFRICA. 2005. General Household Survey. Pretoria: Government Printers.

STATISTICS SOUTH AFRICA. 2007. General Household Survey. Pretoria: Government Printers.

TERRE BLANCHE, M., DURRHEIM, K. \& PAINTER, D. (eds) 2006. Research in practice. Cape Town: UCT Press.

UNICEF. 2005. ANNUAL REPORT FOR SOUTH AFRICA. Pretoria: United Nations Children's Fund.

VAN RENSBURG, D. \& GREEN, S. 2006. Grootmoeders in Kayamandi se ervaring van familiepleegsorg. Social Work/Maatskaplike Werk, 42(3/4):327-340.

WALLACE, G. 2001. Grandparent caregivers: emerging issues in elder law and social work practice. Journal of Gerontological Social Work, 34(3):127-136.

WILD, L. 2001. The psychological adjustment of children orphaned by AIDS. Southern African Journal of Child and Adolescent Mental Health, 13(1):3-25.

WILSON, D.B. \& CHIPUNGA, S.S. 1996. Introduction for Child Welfare League of America (CWLA). Child Welfare, 75(5):387-395.

WORDEN, J.W. 1996. Grief and children: when a parent dies. New York: Guilford Press.

Although this research was funded by the Nelson Mandela Children's Fund, the article has been written by the authors and reflects their interpretations of the research findings and not necessarily the views of the Nelson Mandela Children's Fund.

Dr Edmarié Pretorius and Prof Eleanor Ross, Department of Social Work, University of the Witwatersrand, Johannesburg, South Africa. 